\title{
SATISFAÇÃO DOS SERVIÇOS: UMA ANÁLISE DA PERCEPÇÃO DOS ÇLIENTES DO BANCO DO BRASIL
}

\author{
SERVICES SATISFACTION: AN ANALYSIS \\ OF THE BANCO DO BRASIL CUSTOMERS' \\ PERCEPTIONS
}

\author{
Recebido 08/01/2012 \\ Aceito $13 / 06 / 2012$ \\ João Renato da Silva Gomes ${ }^{1}$ \\ Vitor Francisco Schuch Jr ${ }^{2}$ \\ Jordana Marques Kneipp ${ }^{3}$ \\ Luciana Aparecida Barbieri da Rosa ${ }^{4}$ \\ Roberto Schoproni Bichueti ${ }^{5}$
}

\section{RESUMO}

O mercado financeiro vem buscando reconhecimento na sua área de atuação através de transações resultantes da disponibilização de plataformas de informática e de telecomunicação. Nesse sentido, procurou-se conhecer o comportamento e a preferência dos clientes em relação aos serviços de autoatendimento, telefônico e Internet Banking do Banco do Brasil na cidade de Santa Maria, RS. A coleta de dados da pesquisa foi desenvolvida através da aplicação de um questionário, fazendo-se uso da estatística descritiva na análise dos dados, visando a obter o perfil socioeconômico dos clientes e da utilização das tecnologias disponíveis, observando-se a percepção e satisfação dos clientes em relação aos produtos e serviços. Primeiramente, foi realizada uma pesquisa bibliográfica, na qual foram analisadas diversas fontes para a construção do embasamento teórico. Na segunda etapa, realizou-se uma pesquisa do tipo survey, com a aplicação de questionários com clientes do Banco do Brasil em áreas de grande circulação da cidade de Santa Maria, RS. A amostra foi caracterizada como não-probabilística e como por conveniência. Através da análise dos resultados, foi possível verificar que o nível de satisfação dos clientes, em relação à maioria dos itens avaliados, é elevado, destacando-se a preferência dos clientes pelo uso do serviço de autoatendimento. Palavras-chave: Qualidade; Satisfação dos serviços, Tecnologia, Setor bancário.

\footnotetext{
${ }^{1}$ Especialista em Gestão Pública pela Universidade Federal de Santa Maria - UFSM, Santa Maria, Rio Grande do Sul, Brasil. E-mail: jrenato84@yahoo.com.br

2 Professor Visitante do Departamento de Ciências Administrativas da Universidade Federal de Santa Maria - UFSM, Santa Maria, Rio Grande do Sul, Brasil. E-mail: vfschuch@gmail.com

${ }^{3}$ Doutoranda no Programa de Pós-Graduação da Universidade Federal de Santa Maria - PPGA/UFSM, Santa Maria, Rio Grande do Sul, Brasil. E-mail: jordana.mk@gmail.com

${ }^{4}$ Mestranda no Programa de Pós-Graduação da Universidade Federal de Santa Maria - PPGA/UFSM, Santa Maria, Rio Grande do Sul, Brasil. E-mail: lucianaaparecidabarbieri@yahoo.com.br

${ }^{5}$ Mestrando no Programa de Pós-Graduação da Universidade Federal de Santa Maria-PPGA/UFSM, Santa Maria, Rio Grande do Sul, Brasil. E-mail: robertobichueti@hotmail.com
} 


\section{ABSTRACT}

The financial market has been seeking recognition in their area of expertise through transactions resulting from the availability of computing platforms and telecommunications. In this sense, we tried to understand the behavior and preferences of customers regarding self-services, internet and phone banking of the Banco do Brasil in Santa Maria, RS. The collection of survey data was developed by applying a questionnaire, using descriptive statistics to analyze the data in order to obtain the socioeconomic profile of clients and the use of available technologies, observing the perception and customer satisfaction for products and services. Firstly, a literature search was conducted, in which several sources were analyzed to construct the theoretical framework. In the second step, we carried out a survey research with questionnaires to customers of the Banco do Brasil in high traffic areas in the city of Santa Maria, RS. The sample was characterized as non-probabilistic and convenience. Through analysis of results, we found that the level of customer satisfaction in relation to the most valued items is high, especially the preference of customers for the self-service. Keywords: Quality; Services satisfaction; Technology, Banking

\section{INTRODUÇÃO}

A instituição bancária tem passado por significativas modificações decorrentes de inúmeros fatores, tais como a competitividade, os avanços tecnológicos e a disponibilidade cada vez maior de tecnologia aos clientes, os quais ganham mais espaço e importância na sua eficiência, tornando-se mais exigentes. Na procura da expansão dos serviços bancários junto aos clientes, os bancos trabalham na disponibilidade de novos canais de acesso. As Agências Virtuais incentivam a comodidade, agilidade e segurança. Esse panorama de atendimento eletrônico está baseado em canais de acesso, como internet, telefone celular, terminais eletrônicos e centrais de atendimento.

Dados recentemente divulgados pela Federação Brasileira dos Bancos (FEBRABAN, 2011) mostram que, em 2010, 23\% das 12,8 bilhões de operações bancárias realizadas no país foram feitas por meio de canais de internet banking, um crescimento de $27,4 \%$ em relação ao ano de 2009. Esses números mostram que os serviços de internet banking já são o segundo meio preferido dos brasileiros, perdendo apenas para os caixas eletrônicos (ATMs), que responderam por $31 \%$ dos atendimentos.

Perante tais informações, torna-se indispensável a implementação de novos modelos de gestão organizacional, a fim de que as instituições estejam mais preparadas para enfrentar o mercado competitivo. Nesse sentido, a avaliação dos serviços de marketing adquire fundamental importância, tendo em vista que representa "um processo social e gerencial pelo qual indivíduos e grupos obtêm o que necessitam e desejam através da criação, oferta e troca de produtos de valor com outros" (KOTLER, 1998, p. 27).

No âmbito do mercado financeiro, as instituições visam à conquista de novos clientes e fidelização dos clientes já existentes, assim como à divulgação de serviços que interessem ao consumidor através das transações de investimento e seguridade que sejam relevantes ao progresso socioeconômico e cultural da comunidade regional e até mesmo do país.

Dentro dessa ótica, as instituições bancárias vêm buscando, ao longo do tempo, entender o comportamento e o nível de satisfação dos consumidores visando à melhoria na imagem e ao reconhecimento na prestação de serviços. Para tanto, pensar em uma estratégia que priorize a qualidade dos serviços se torna fundamental para a concretização dos reais interesses dessas organizações.

Para atender a esse questionamento, o objetivo desse estudo é analisar a satisfação dos clientes das agências do Banco do Brasil na cidade de Santa Maria, RS, com relação à qualidade dos serviços de atendimento oferecidos, identificando as razões para a sua escolha e as principais dificuldades para a sua utilização. 


\section{FIDELIZAÇÃO DO CLIENTE E QUALIDADE DO SERVIÇO}

A construção de relacionamentos duradouros e de longo prazo com os clientes, de modo a satisfazer suas necessidades e expectativas, representa uma estratégia cada vez mais priorizada pelas empresas.

Para se estabelecer um relacionamento eficaz e de longo prazo, não é suficiente apenas saber se o cliente está satisfeito com o serviço prestado pela empresa, também é necessário conhecer as necessidades do cliente para encurtar os laços de relacionamento e, dessa forma, fidelizar o cliente.

Para Kotler (1998, p.30), marketing de relacionamento "é a prática da construção de relações satisfatórias a longo prazo, com partes-chaves - consumidores, fornecedores e distribuidores - para se reter sua preferência e seus negócios a longo prazo".

As expectativas dos clientes são influenciadas pela experiência anterior de compra, recomendação de amigos e colegas e informações e promessas das empresas e dos concorrentes. A satisfação dos clientes e a qualidade do atendimento e dos serviços nunca podem ser consideradas como definitivas, e sim um processo dinâmico e inacabado.

Para Araújo (2001, p. 211), qualidade, resumidamente, poderia ser definida como a busca pela perfeição com a finalidade de agradar a clientes cada vez mais conscientes das facilidades de consumo e variedades de empresas a oferecer produtos. Qualidade, ademais, é uma filosofia em que a eliminação do chamado retrabalho e a obsessão pelo "defeito zero" são regras inafastáveis para as organizações que desejam permanência e lucro.

Zeithaml e Bitner (2003) propõem as definições de qualidade dos serviços como:

a) Confiabilidade: habilidade de desempenho do serviço oferecido confiante e rigorosamente.

b) Nível de resposta: boa vontade para orientar os clientes e prestação imediata do serviço. do serviço.

c) Competência: domínio das habilidades necessárias e conhecimento do desempenho

d) Cortesia: educação, respeito, consideração e cordialidade do pessoal de contato.

e) Credibilidade: confiabilidade e honestidade do prestador de serviço.

f) Segurança: inexistência de perigo, risco ou dúvida.

g) Acesso: facilidade de contato.

h) Comunicação: manter o cliente informado na linguagem que ele possa entender e ouvi-lo.

i) Conhecimento do consumidor/cliente: fazer esforço para conhecer os clientes e suas necessidades.

j) Tangibilidade: aparência das instalações, dos equipamentos, do pessoal e dos materiais de comunicação.

Castro e Gouvêa (2011) propõem algumas características para avaliação de serviços bancários, a partir de um modelo denominado e-banking. De acordo com Castro e Gouvêa (2011), o modelo e-banking contempla as seguintes dimensões:

a) Tangibilidade: refere-se aos aspectos que transmitem algo de concreto sobre os serviços, a partir das seguintes características: consulta e navegação do site; design e layout gráfico; compatibilidade das tarifas dos serviços do netbanking com os benefícios oferecidos; disponibilidade do material associado com os serviços prestados no netbanking; aparência visual do material associado com os serviços prestados no netbanking; velocidade de carregamento dos sites; facilidade e rapidez para se cadastrar; clareza na linguagem do netbanking.

b) Confiabilidade: relaciona-se a realização do serviço de forma precisa e confiável, de acordo com o esperado. As características inerentes a esta dimensão são: cumprimento do serviço 
no prazo determinado para executá-lo; realização do serviço conforme especificado pelo cliente; execuções de tarefas sem erros do sistema; envio de informações pré e pós a execução dos serviços.

c) Presteza: refere-se ao desimpedimento e a disposição de entender os problemas e as dificuldades dos clientes de forma positiva. Engloba as seguintes características: boa vontade dos empregados; interesse da instituição financeira na solução de problemas dos clientes; desimpedimento dos empregados responsáveis pelo netbanking para esclarecer dúvidas dos seus clientes; suficiência das informações contidas nos menus de ajuda e tutoriais do netbanking.

d) Segurança: relaciona-se com a sensação oferecida aos clientes a partir da reputação da instituição financeira, do desempenho do serviço virtual e da utilização de soluções que evitem causar quaisquer danos em dados ou recursos de rede, na forma de destruição, revelação, modificação de dados etc. As características desta dimensão são: ações preventivas dos responsáveis pelo netbanking; acesso aos serviços do netbanking sem restrições decorrentes de problemas técnicos no seu sistema; reputação da instituição financeira responsável pelos serviços de netbanking; segurança das transações via netbanking; segurança transmitida pelo desempenho do site.

e) Empatia: representa a prestação de cuidados e atenção individual aos clientes. As características desta dimensão são: nível de atenção individual a cada cliente; conveniência dos horários de funcionamento; padrão de excelência no serviço prestado aos seus clientes; preocupação com a identificação das necessidades e dificuldades específicas dos clientes.

Dada a importância de atendimento das expectativas dos clientes, torna-se importante compreender os principais fatores que influenciam o seu comportamento. Esse assunto será discutido no capítulo a seguir apresentado.

\section{FATORES QUE INFLUENCIAM O COMPORTAMENTO DO CONSUMIDOR}

Para lançar, no mercado, produtos que atinjam os objetivos do conceito de marketing ou mesmo manter um nível satisfatório de atendimento, torna-se necessário entender a razão e a forma pela qual os consumidores realizam suas compras. Somente através do entendimento desse processo, será possível viabilizar produtos e serviços que atendam exatamente os desejos e as necessidades dos consumidores (LAS CASAS, 1997).

Para Kotler (1998), o processo de compra inicia-se quando o comprador reconhece um problema ou uma necessidade. Ele percebe a diferença entre sua situação atual e uma situação desejada. A necessidade pode ser impulsionada por estímulos internos e externos, e cabe ao profissional de marketing identificar as circunstâncias que ativam uma necessidade específica.

A segunda etapa do processo de compra é a busca de informações, que acontece quando o cliente está realmente interessado na compra. Para Kotler (1998), é de grande interesse do profissional de marketing conhecer as principais fontes de informação que o consumidor recorrerá e a influência relativa que cada uma delas terá sobre a decisão de compra. As fontes de informações do consumidor são classificadas em quatro grupos: fontes pessoais (família, amigos, vizinhos, conhecidos); fontes comerciais (propaganda, vendedores, trevendedores, emblagens, displays); fontes públicas (mídia de massa, organizações de consumidores); e fontes experimentais (manuseio, exame, uso o produto).

A próxima etapa é a decisão da compra, que é o momento em que o consumidor decide pela compra do produto, após passar pela avaliação das alternativas disponíveis e pela identificação daquela que lhe trará maiores vantagens.

A última fase do processo é a do pós-compra. Para Las Casas (1997), a teoria mais importante que se refere a sentimentos pós-compra é dissonância cognitiva. De acordo com essa 
teoria, não existe um indivíduo harmonioso entre atitudes, crenças e cognição, após uma tomada de decisão. $O$ indivíduo entrará em estado de ansiedade, que poderá ser aumentada ou diminuída de acordo com alguns fatores como: o grau de importância psíquica e financeira da decisão e o número elevado de alternativas.

Em função disso, as empresas precisam focar seus esforços para assegurar a satisfação dos seus clientes em todas as etapas do processo de compra.

As informações e a tecnologia têm importância fundamental para os serviços financeiros que são foco desse estudo. Assim, na sequência, são destacados os principais aspectos que influenciam a tomada de decisão dos clientes.

\section{O SISTEMA DE INFORMAÇÃO E O USO DA TECNOLOGIA}

As empresas devem organizar o fluxo de informações de marketing para que seus administradores de marketing tenham dados e informações para a tomada de decisão. Segundo Kotler (1998), o Sistema de Informações de Marketing (SIM) pode ser definido como:

Um Sistema de Informações de Marketing consiste de pessoas, equipamentos e procedimentos para coletar, selecionar, analisar, avaliar e distribuir informações de marketing que sejam necessárias, oportunas e precisas para os tomadores de decisões de marketing. (KOTLER, 1998, p. 111).

Las Casas (1997) aponta múltiplas vantagens às empresas que utilizam o SIM. Além de ajudá-la a conhecer melhor os seus consumidores, o mesmo ajuda a estabelecer as estratégias de marketing da empresa à luz da realidade do mercado de atuação. O SIM fornece informações que podem servir para o estabelecimento do planejamento anual de marketing. Além disso, proporciona uma forma constante de dados que facilitam a função de controle do administrador.

Para que as instituições proporcionem um alto nível de satisfação entre os clientes, é necessário tornar a empresa orientada mais para as necessidades de seus clientes e mais habilitada para atrair novos clientes (KOTLER, 1998).

A emergência das tecnologias digitais, ou tecnologias de informação e da comunicação, pode ser vista como um dos fatores determinantes para a constituição de uma cultura contemporânea marcada, dentre outros aspectos, por novas práticas de comunicação e, em consequência, sujeita a transformação em curso, ainda não aprendidas plenamente (PEREIRA, 2006).

Quando são analisadas as transações bancárias e as formas com que estas podem ser conduzidas, tais interações transacionais podem ocorrer de forma pessoal e presencial, que proporciona interação humana, podem-se utilizar Caixas Eletrônicos (ATMs - Automated Tellers Machines), utilizar o atendimento bancário via telefone ou, ainda, adotar as mais modernas tecnologias vinculadas à internet através do on-line banking (HAYTKO e SIMMERS, 2009; CURRAN e MEUTER, 2005).

Outra forma usual de atendimento bancário é através da Internet. Esse ambiente virtual proporciona um atendimento diferenciado ao cliente, sendo considerado atualmente como o centro do e-Banking. A Internet dispõe de recursos que as empresas utilizam para trocar informações internamente ou para se comunicarem externamente com outras organizações (LAUDON e LAUDON, 2004). Essa realidade pode ser observada facilmente em ambientes bancários onde existem, atualmente, transações bancárias ocorrendo em tempo real, sendo possíveis em virtude da própria Internet. Seu uso tem o potencial de revolucionar a forma de operação das organizações, proporcionando ganhos significativos de produtividade, reinventando processos, reduzindo os custos operacionais e eliminando funções que não 
agregam valor (TURBAN et al., 1999).

As inovações do Internet Banking estão bastante difundidas, e estudos específicos (PIKKARAINEN et al., 2006) demonstram que seus usuários apresentam um certo grau de satisfação. Para os bancos que adotam essa tecnologia, além de proporcionar um aumento de valor a ser entregue aos clientes, esta representa uma oportunidade de redução de custos operacionais e de aumento de eficiência.

Porém, Fabeny (2007) coloca que ainda existe certa resistência com relação à utilização da internet para serviços bancários. Para o autor, a principal restrição se relaciona ao medo dos usuários de que sua conta seja violada ou que outras pessoas possam ter acesso à transação enquanto a mesma estiver em curso.

Com uma visão, em linhas gerais, mais utilitarista do sistema, Diniz (2001) e Costa Filho (1996) definem o netbanking como qualquer solução de informática e de telecomunicações capaz de permitir o acesso personalizado e a distribuição de serviços bancários e não bancários quando os clientes quiserem e de onde estiverem, sem que estes precisem locomover-se de suas casas ou de seus escritórios até uma agência bancária, ou seja, prescindindo-se da rede de agências.

O Modelo de Aceitação de Tecnologia (TAM - Technology Acceptance Model) foi proposto por Davis (1986). A principal finalidade do Modelo de Aceitação de Tecnologia é prever e explicar a aceitação de novas tecnologias pelo seu usuário final, por meio de crenças percebidas (utilidade e facilidade). Assim, este é normalmente utilizado para entender o porquê de o usuário aceitar ou rejeitar a Tecnologia de Informação e a maneira de melhorar a aceitação, oferecendo, desse modo, um suporte para prever e explicar a aceitação.

Esse modelo teoriza que uma intenção comportamental do indivíduo para usar um sistema é determinada por duas crenças, facilidade percebida de uso e utilidade percebida, sendo que ambas mediam completamente os efeitos das variáveis externas, como características do sistema, processo de desenvolvimento, treinamento, na intenção de uso (DIAS, ZWICKER e VICENTIN, 2003).

Henrique (2001), em pesquisa realizada nos meses de julho e agosto 2000, nas salas de autosserviço do Banco do Brasil, avaliou o grau de satisfação do cliente bancário com a utilização das tecnologias de informática e telecomunicações, na realização dos serviços bancários, na cidade de Porto Alegre - RS. O autor (2001) analisou fatores sobre postos de autoatendimento, processamento de transações, comunicação com clientes, segurança, atendimento nas centrais telefônicas e erros relacionados a computadores e concluiu que a satisfação dos clientes Banco do Brasil está próxima ao nível máximo em praticamente todos os aspectos referentes às centrais telefônicas, ao autoatendimento, ao Internet Banking e à empresa como um todo.

Em razão de o foco temático do estudo estar orientado para a qualidade e satisfação dos serviços bancários, no capítulo a seguir apresentado, são relacionados alguns aspectos pertinentes em relação ao setor financeiro e ao Banco do Brasil, objeto da pesquisa realizada.

\section{O SISTEMA FINANCEIRO E O BANCO DO BRASIL}

O mercado financeiro se caracteriza por um conjunto de instituições que possibilitam a transferência de recursos ofertados para os tomadores e se divide em Mercado de Crédito e Mercado de Capitais. Sua função é gerir investimentos e poupança, seu desenvolvimento se da através do Aprofundamento, que se dá por mais empréstimos e depósitos e também através do Alargamento, que são mais bancos, seguradoras, poupadores e tomadores. (ANDREZO e LIMA, 2011).

A partir da década de 70, uma série de mudanças passou a impactar e transformar o ambiente financeiro no Brasil. Para Segnini (1997), fusões, incorporações e privatização de bancos 
estatais levaram a um conjunto de medidas que objetiva a minimização dos custos:

a) Evolução e uso intensivo das tecnologias de informação, informática e telemática permitiram automatizar serviços para reduzir custos e aumentar a segurança e a qualidade dos serviços disponibilizados para uma parcela da população, via fax, telefones, computadores em escritórios e residências;

b) Terceirização de um volume crescente de trabalhos considerados "não bancários", como transporte, segurança, limpeza, engenharia e manutenção de prédios e equipamentos, restaurante, desenvolvimento de softwares. Posteriormente, serviços bancários também passaram a ser terceirizados, tais como análise de crédito, compensação de cheques e centrais de atendimento.

O sistema financeiro brasileiro passou por profundas alterações na sua estrutura e na sua regulação, ao longo da década de 1990. Esse processo esteve, em grande medida, associado ao contexto de estabilização monetária e de abertura do setor ao capital externo que se observou no período. A redução das receitas inflacionárias, decorrente do Plano Real, ocasionou uma diminuição da participação das instituições financeiras no valor adicionado no Brasil. Nesse contexto, é lançado o Programa de Reestruturação e Fortalecimento do Sistema Financeiro (PROER) e o seu análogo para o setor público, o Programa de Estímulo à Redução do Setor Público no Sistema Financeiro (PROES), cuja consequência mais marcante foi o processo de concentração observado no sistema financeiro do País. Outro movimento resultante do processo de reestruturação do sistema financeiro ao longo do período foi o acentuado crescimento do investimento externo direto no setor, elevando as participações dos bancos com controle estrangeiro nos ativos bancários e nos depósitos e créditos do sistema bancário, de níveis inferiores a 10\%, em 1993, para níveis em torno de $20 \%$ em 2000. (CAVALCANTE, 2002).

O processo de modernização e automação pelo qual passaram as instituições bancárias no Brasil decorreu da forte pressão competitiva a que se expuseram as suas organizações com o processo de estabilização monetária e, em menor escala, com a internacionalização do sistema. (TEIXEIRA e CAVALCANTE, 2005).

As inovações mais significativas do segmento refletem a maior valorização dos softwares no processo de automação bancária, segmento este dificilmente percebido pelos usuários, mas que é o cerne do processo e seu grande elemento dinamizador. Entre as inovações mais bemsucedidas e mais promissoras, destacam-se as transações via telefone celular, os certificados digitais e as soluções em segurança da informação. (GOUVEIA, 2007).

O Banco do Brasil vem ampliando sua presença internacional, contando com mais de 40 pontos de atendimento no exterior, divididos em agências, subagências, unidades de negócios/escritórios e subsidiárias. Com larga experiência, de mais de 65 anos em operações de comércio internacional, produtos e serviços a clientes no exterior, além de embaixadas e consulados, o Banco do Brasil é o parceiro ideal para apoiar seus negócios também fora do Brasil. (BANCO DO BRASIL, 2011).

$O$ estudo realizado buscou identificar essa percepção em clientes de agências do Banco do Brasil localizadas na cidade de Santa Maria, RS. Os procedimentos metodológicos utilizados são destacados no próximo capítulo do estudo.

\section{METODOLOGIA}

O estudo desenvolvido caracteriza-se, quanto aos objetivos, como descritivo, uma vez que esse tipo de estudo pretende descrever os fatos e fenômenos de determinada realidade (TRIVINOS, 1987).

Quanto à abordagem, este estudo caracteriza-se como quantitativo. De acordo com o Richardson (1999), o método quantitativo marca-se pelo emprego da quantificação na coleta e no tratamento das informações, por meio de técnicas estatísticas. Quanto à natureza da investigação, 
neste trabalho, utiliza-se uma metodologia quantitativa de caráter exploratório, que, segundo Mattar Neto (2002), proporciona ao pesquisador um maior conhecimento sobre o tema ou problema de pesquisa em perspectiva.

O método survey foi utilizado para o desenvolvimento do estudo. O survey é um método quantitativo que busca a obtenção de dados ou informações sobre características, ações ou opiniões de determinado grupo de pessoas, indicado como representante de uma população-alvo, por meio de um instrumento de pesquisa, normalmente um questionário. (PINSONNEAULT e KRAEMER,1993).

Para identificar o grau de utilização ou de dificuldade de utilização dos clientes de perfil exclusivo, familiarizados ou não com a Internet banking, neste trabalho, utilizou-se, como amostra de pesquisa, a maior instituição financeira brasileira, o Banco do Brasil. A população de interesse corresponde aos usuários correntes, a pessoas físicas que utilizam os serviços do Banco do Brasil S.A na cidade de Santa Maria. O Banco do Brasil se caracteriza por ser uma das maiores instituições financeiras no segmento de múltiplos bancos - instituições financeiras que podem realizar todas as operações ativas e passivas intrínsecas a cada um dos tipos individuais de instituição (bancos comerciais, investimento e desenvolvimento) atuantes na cidade de Santa Maria.

\subsection{Procedimentos para a coleta dos dados}

A coleta de dados foi realizada por meio de um questionário aplicado em julho de 2011. Os questionários foram aplicados de forma presencial em locais de grande circulação de pessoas. Para tanto, foram escolhidos os principais Shopping Centers da cidade de Santa Maria, localizados em áreas centrais. No total, foram aplicados 100 questionários com clientes do Banco do Brasil, sendo a amostra caracterizada como não-probabilística e por acessibilidade.

\subsection{Instrumento de coleta de dados}

O instrumento de coleta de dados foi elaborado a partir do estudo desenvolvido por Henrique (2001), que teve como objetivo avaliar o grau de satisfação do cliente bancário com a utilização das tecnologias de informática e telecomunicações, na realização dos serviços bancários, na cidade de Porto Alegre - RS. Além disso, algumas variáveis foram retiradas da pesquisa de Castro e Gouvêa (2011), que buscou identificar a opinião dos clientes em relação ao desempenho dos serviços bancários via internet, nas dimensões de qualidade proposta pelo modelo e-banking.

O questionário foi dividido em quatro blocos. O Bloco I busca identificar o perfil dos respondentes. O segundo bloco identifica a frequência de utilização dos terminais de autoatendimento, dos serviços telefônicos e do internet banking do Banco do Brasil. O terceiro bloco avalia a satisfação com o autoatendimento, atendimento telefônico e internet banking do Banco do Brasil. Por fim, o último bloco avalia a importância que os clientes do referido banco atribuem a algumas características em prestadoras de serviços.

\subsection{Análise de dados}

Os dados foram tabulados e analisados utilizando-se os programas Excel e SPSS. Os resultados foram apresentados em forma de tabelas e gráficos, analisados individualmente pelo pesquisador e descritos em forma de texto.

Em alguns itens, os dados foram analisados pelo nível de satisfação ou grau de influência, utilizando uma escala de Likert de 05 pontos, sendo: muito insatisfeito (1), insatisfeito (2), nem satisfeito nem insatisfeito (3), satisfeito (4) e muito satisfeito (5). 


\section{ANÁLISE E DISCUSSÃO DOS RESULTADOS}

A apresentação dos resultados desta pesquisa divide-se em quatro etapas. Primeiramente, descreve-se o perfil da amostra consultada. Em seguida, apresenta-se a avaliação dos serviços utilizados pelos usuários. $O$ terceiro item avalia a satisfação dos usuários em relação aos serviços prestados e, por fim, a avaliação da satisfação geral deste sobre tais serviços.

\subsection{Perfil dos participantes da pesquisa}

Na primeira parte da pesquisa, é avaliado o perfil dos respondentes em relação ao sexo, à idade, à escolaridade, à renda mensal, ao tempo como correntista e à agência de origem do correntista.

Na tabela 1, são apresentados os dados relativos à composição do perfil dos clientes pesquisados.

Tabela 1 - Perfil dos respondentes

\begin{tabular}{|c|c|c|c|c|}
\hline & Variáveis & Indicadores & $\mathrm{N}$ & $\%$ \\
\hline \multirow[t]{2}{*}{1.} & Sexo & Feminino & 61 & 61,0 \\
\hline & & Masculino & 39 & 39,0 \\
\hline \multirow[t]{5}{*}{2.} & Idade & Até 20 anos & 21 & 21,0 \\
\hline & & De 20 a 30 anos & 50 & 50,0 \\
\hline & & De 31 a 40 anos & 16 & 16,0 \\
\hline & & De 41 a 50 anos & 11 & 11,0 \\
\hline & & Acima de 50 anos & 1 & 1,0 \\
\hline \multirow[t]{4}{*}{3.} & Escolaridade & Ensino Fundamental & 4 & 4,0 \\
\hline & & Ensino Médio & 30 & 30,0 \\
\hline & & Ensino Superior & 48 & 48,0 \\
\hline & & Pós-Graduação & 18 & 18,0 \\
\hline \multirow[t]{5}{*}{4.} & Renda mensal & Até $\mathrm{R} \$ 1.500,00$ & 54 & 54,0 \\
\hline & & De $R \$ 1.501,00$ a $R \$ 2.500,00$ & 14 & 14,0 \\
\hline & & e $R \$ 2.501,00$ a $R \$ 3.500,00$ & 15 & 15,0 \\
\hline & & De $R \$ 3.501,00$ a $R \$ 5.000,00$ & 13 & 13,0 \\
\hline & & De $\mathrm{R} \$ \mathbf{5} 5.001,00$ a $\mathrm{R} \$ 10.000,00$ & 04 & 4,0 \\
\hline \multirow{4}{*}{\multicolumn{2}{|c|}{ 5. Tempo em que é correntista }} & Menos de 1 ano & 20 & 20,0 \\
\hline & & De 1 a 2 anos & 21 & 21,0 \\
\hline & & De 2 a 5 anos & 26 & 26,0 \\
\hline & & Acima de 5 anos & 4 & 4,0 \\
\hline
\end{tabular}

Os dados da tabela 1 permitem observar que o perfil predominante dos participantes da pesquisa é formado por pessoas do sexo feminino, que têm idade entre 20 e 30 anos, escolaridade superior, renda de até $1.500,00$ reais e que são correntistas e usuários dos serviços do Banco do Brasil há até 5 anos.

Em relação ao grau de escolaridade, tem-se que acima de $60 \%$ dos participantes possuem curso superior ou pós-graduação. 
Esse resultado já era esperado, na medida em que os pontos de coleta de dados da pesquisa se situaram em áreas de elevada circulação de pessoas e em áreas centrais da cidade.

A presença de elevado percentual de pessoas jovens pode ser explicada pela presença significativa de uma população economicamente ativa e, também, pela presença de estudantes, principalmente oriundos das agências Niederauer e Mariano da Rocha, próximas da Universidade Federal de Santa Maria.

No gráfico 1, a seguir relacionado, são representadas as agências de origem dos participantes da pesquisa.

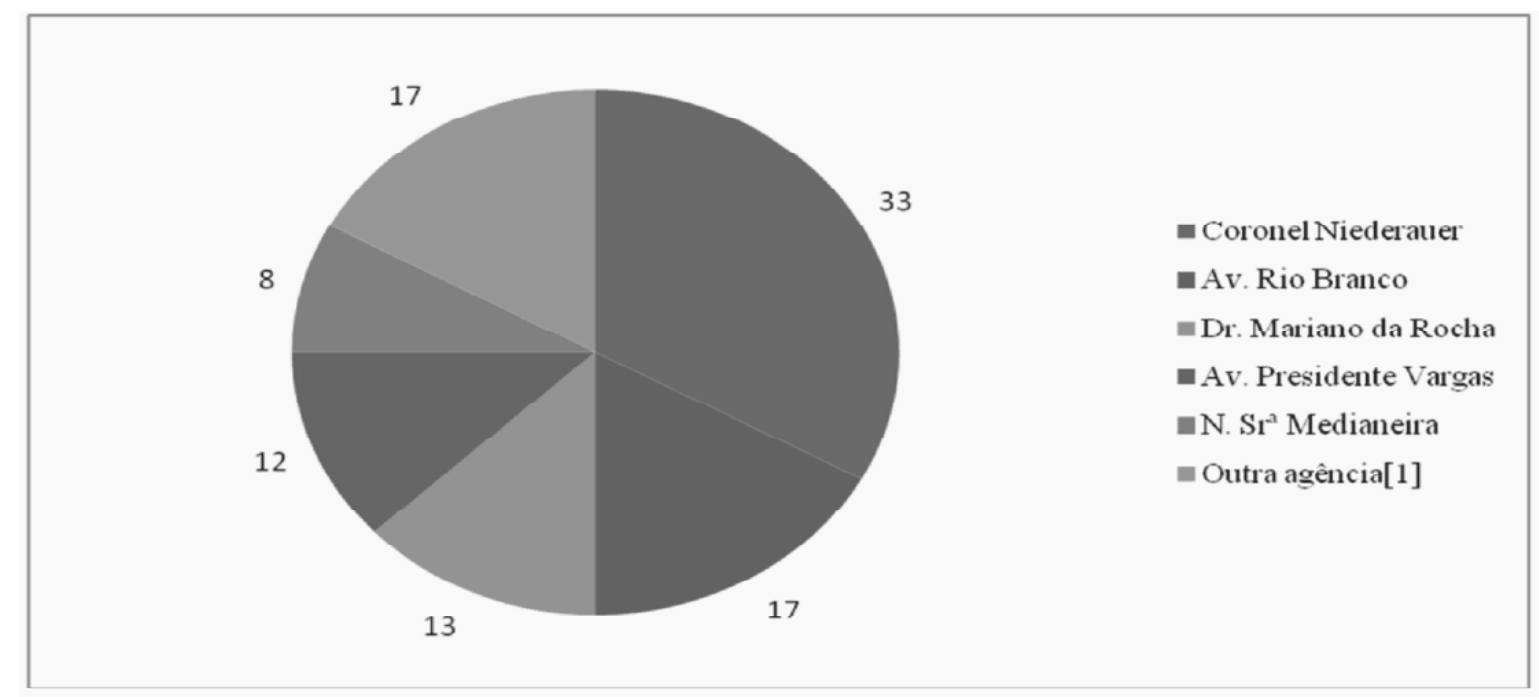

Gráfico 1 - Agência de origem dos respondentes da pesquisa

Como é possível verificar no gráfico 1 , as agências que se destacaram em termos de representatividade na pesquisa foram: Coronel Niederauer e Av. Rio Branco.

Desse modo, diante da análise dos dados de identificação, foi possível verificar o perfil predominante dos clientes pesquisados. No próximo item, são abordados os resultados relativos à segunda parte do questionário, na qual é analisada a percepção do cliente sobre os serviços prestados pelo Banco do Brasil.

\subsection{Avaliação da utilização dos serviços pelos usuários}

O Banco do Brasil oferece, aos seus clientes, serviços de atendimento na agência (autoatendimento), atendimento telefônico e pela internet (internet banking). No entanto, está sempre buscando um diferencial, visando à adequação do produto às necessidades de clientes ocasionais que podem se tornar regulares e para que os clientes regulares se tornem fiéis à instituição.

A tabela 2 apresenta a descrição dos resultados encontrados para cada item analisado nesse aspecto. 
Tabela 2 - Utilização dos serviços disponíveis

\begin{tabular}{|c|c|c|c|c|c|c|c|c|c|c|c|c|c|c|}
\hline \multirow[t]{2}{*}{-} & \multicolumn{2}{|c|}{ Nunca } & \multicolumn{2}{|c|}{$\begin{array}{l}\text { Menos de } \\
\text { uma vez }\end{array}$} & \multicolumn{2}{|c|}{$\begin{array}{l}\text { Uma vez } \\
\text { por mês } \\
\text { (2) }\end{array}$} & \multicolumn{2}{|c|}{$\begin{array}{c}\text { Uma vez a } \\
\text { cada } 15 \\
\text { dias } \\
(3)\end{array}$} & \multicolumn{2}{|c|}{$\begin{array}{c}\text { Uma vez } \\
\text { por semana } \\
(4)\end{array}$} & \multicolumn{2}{|c|}{$\begin{array}{c}\text { Todos os } \\
\text { dias } \\
(5)\end{array}$} & \multicolumn{2}{|c|}{ Total } \\
\hline & $\mathrm{N}$ & $\%$ & $\mathbf{N}$ & $\%$ & $\mathbf{N}$ & $\%$ & $\mathbf{N}$ & $\%$ & $\mathbf{N}$ & $\%$ & $\mathbf{N}$ & $\%$ & $\mathbf{N}$ & $\%$ \\
\hline $\begin{array}{l}\text { Utilização de } \\
\text { terminais de } \\
\text { auto- } \\
\text { atendimento }\end{array}$ & - & - & 6 & 6,0 & 19 & 19,0 & 26 & 26,0 & 45 & 45,0 & 4 & 4,0 & 100 & 100 \\
\hline $\begin{array}{l}\text { Utilização de } \\
\text { serviços } \\
\text { telefồnicos }\end{array}$ & 50 & 50,0 & 33 & 33,0 & 6 & 6,0 & 5 & 5,0 & 5 & 5,0 & 1 & 1,0 & 100 & 100 \\
\hline $\begin{array}{l}\text { Utilização de } \\
\text { serviços via } \\
\text { Internet }\end{array}$ & 47 & 47,0 & 19 & 19,0 & 15 & 15,0 & 12 & 12,0 & 5 & 5,0 & 2 & 2,0 & 100 & 100 \\
\hline
\end{tabular}

Os dados contidos na tabela 2 permitem observar a preferência dos clientes pela utilização de terminais de autoatendimento, o que implica na sua utilização nas agências ou em terminais 24 horas.

O serviço telefônico e de internet apresentam baixa frequência de uso, destacando-se o elevado percentual de clientes que nunca acessaram os serviços. Os principais motivos da não utilização desses serviços são relacionadas nos gráficos 2 e 3 .

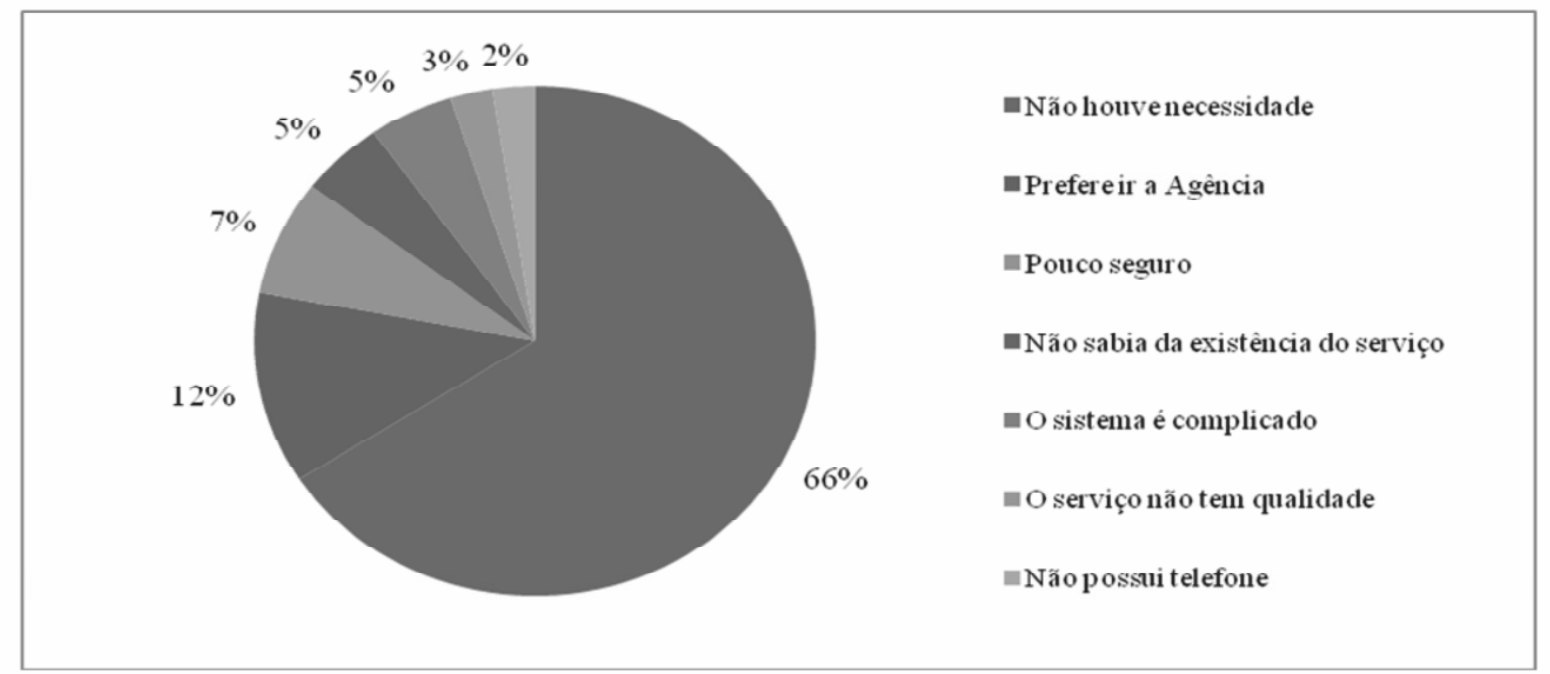

Gráfico 2 - Motivos da não utilização do serviço telefônico

O gráfico 2 apresenta os principais motivos elencados pelos respondentes que justificam a não utilização do serviço telefônico. Na percepção da maior parte dos clientes, o principal motivo se encontra na inexistência de necessidade. A preferência por frequentar a agência é outro aspecto relevante. Chama a atenção o fato de parte dos clientes desconhecerem o serviço disponibilizado pelo banco.

A frequente citação, por parte dos clientes entrevistados, de que não houve necessidade de utilizar o atendimento telefônico pode ser interpretada como se o atendimento telefônico estivesse sendo relacionado a uma situação emergencial. De outro modo, em uma situação normal, a ida à agência teria maior preferência. 
Somando-se outros dois fatores - preferir ir à agência e achar pouco seguro - pode-se concluir que a segurança é fator importante na avaliação dos clientes. Segurança que pode estar ligada à tomada de decisão em algumas transações e não somente ao sigilo de dados.

No gráfico 3, são apresentados os principais aspectos que explicam a não utilização do serviço de internet banking.

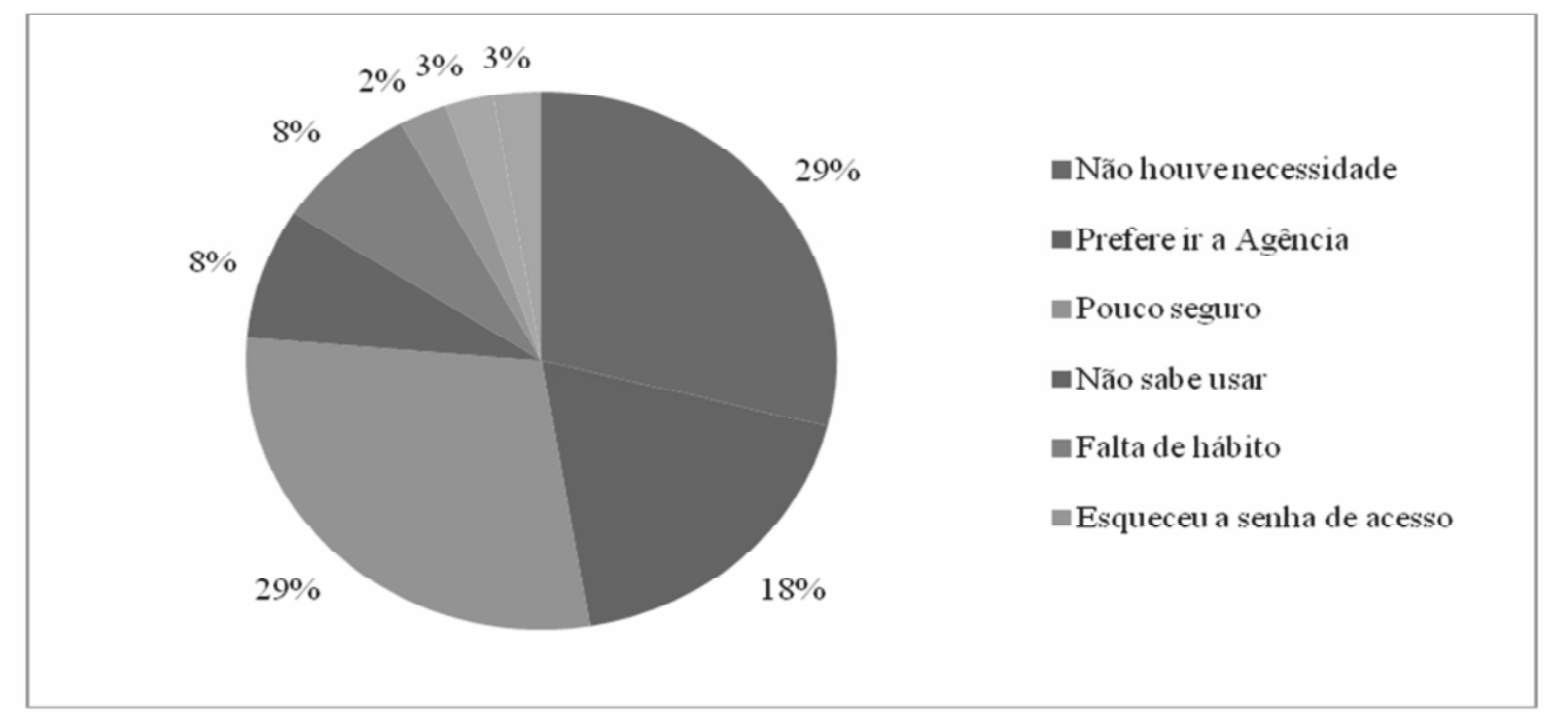

Gráfico 3 - Motivos da não utilização do serviço de internet

A inexistência de necessidade, a falta de confiança na segurança do sistema e a preferência por frequentar as agências são os principais aspectos destacados pelos clientes, conforme dados apresentados no gráfico 3 . As dificuldades no uso do sistema e a falta de hábito são outros aspectos mencionados e que evidenciam a necessidade de desenvolvimento da cultura e do suporte aos clientes.

Para Fabeny (2007), a principal restrição na utilização do internet banking está relacionada ao medo dos usuários de que sua conta seja violada ou de que outras pessoas possam ter acesso a transação.

Tomando-se como referência a pesquisa aplicada, é elevado o índice de pessoas que não utilizam os serviços de internet banking. É válido ressaltar que a população estudada tem, relativamente, renda e nível educacional elevados, são conhecedores de comunicação digital e estão indecisos quanto ao uso do serviço.

Os dados revelam que os entrevistados estão acostumados ao ambiente digital, porém grande parte deles não utiliza a internet banking, possivelmente em função do desconhecimento do serviço, de insegurança na execução das tarefas, da falta de confiança no sistema internet e da falta de confiança nos dados da internet banking.

\subsection{Avaliação da satisfação do usuário em relação aos serviços prestados}

\subsubsection{Satisfação do usuário com o serviço de autoatendimento}

Os principais aspectos que influenciam a satisfação com os serviços de autoatendimento quanto às operações e à estrutura disponível são apresentados na tabela 3. 
Tabela 3 - Satisfação com os serviços de autoatendimento

\begin{tabular}{|c|c|c|c|c|c|c|c|c|c|c|c|c|c|c|}
\hline \multirow[t]{2}{*}{$\begin{array}{l}\text { Satisfação com o } \\
\text { autoatendimento }\end{array}$} & \multicolumn{2}{|c|}{$\begin{array}{l}\text { Não } \\
\text { resposta }\end{array}$} & \multicolumn{2}{|c|}{$\begin{array}{c}\text { Muito } \\
\text { Insatisfeito } \\
\text { (1) }\end{array}$} & \multicolumn{2}{|c|}{ (2) } & \multicolumn{2}{|c|}{ (3) } & \multicolumn{2}{|c|}{ (4) } & \multicolumn{2}{|c|}{$\begin{array}{l}\text { Muito } \\
\text { satisfeito } \\
\text { (5) }\end{array}$} & \multicolumn{2}{|c|}{ Total } \\
\hline & $\mathrm{N}$ & $\%$ & $\mathrm{~N}$ & $\%$ & $\mathrm{~N}$ & $\%$ & $\mathrm{~N}$ & $\%$ & $\mathrm{~N}$ & $\%$ & $\mathrm{~N}$ & $\%$ & $\mathrm{~N}$ & $\%$ \\
\hline- & 6 & 6,0 & 2 & 2,0 & 12 & 12,0 & 29 & 29,0 & 34 & 34,0 & 17 & 17,0 & 100 & 100 \\
\hline $\begin{array}{l}\text { 2. Identificação dos } \\
\text { terminais para saques, } \\
\text { extratos,saldos, cheques... }\end{array}$ & 3 & 3,0 & 2 & 2,0 & 3 & 3,0 & 19 & 19,0 & 38 & 38,0 & 35 & 35,0 & 100 & 100 \\
\hline $\begin{array}{l}\text { 3. Disponibilidade de } \\
\text { dinheiro nas máquinas de } \\
\text { autoatendimento }\end{array}$ & 2 & 2,0 & 4 & 4,0 & 2 & 2,0 & 17 & 17,0 & 37 & 37,0 & 38 & 38,0 & 100 & 100 \\
\hline $\begin{array}{l}\text { 4. Tempo de espera na } \\
\text { fila dos terminais de } \\
\text { autoatendimento }\end{array}$ & 4 & 4,0 & 6 & 6,0 & 22 & 22,0 & 30 & 30,0 & 26 & 26,0 & 12 & 12,0 & 100 & 100 \\
\hline $\begin{array}{l}\text { 5. Localização dos postos } \\
\text { de autoatendimento do } \\
\text { banco }\end{array}$ & 4 & 4,0 & 6 & 6,0 & 6 & 6,0 & 24 & 24,0 & 33 & 33,0 & 27 & 27,0 & 100 & 100 \\
\hline $\begin{array}{l}\text { 6. Autoate ndimento em } \\
\text { qualquer ponto do país }\end{array}$ & 8 & 8,0 & 3 & 3,0 & 8 & 8,0 & 17 & 17,0 & 28 & 28,0 & 36 & 36,0 & 100 & 100 \\
\hline $\begin{array}{l}\text { 7. Visualização de } \\
\text { comprovante das } \\
\text { operações nos terminais. }\end{array}$ & 1 & 1,0 & 6 & 6,0 & 4 & 4,0 & 10 & 10,0 & 34 & 34,0 & 45 & 45,0 & 100 & 100 \\
\hline $\begin{array}{l}\text { 8. Limite de saque diário } \\
\text { permitido nos termin ais } \\
\text { de autoatendimento }\end{array}$ & 6 & 6,0 & 6 & 6,0 & 16 & 16,0 & 25 & 25,0 & 32 & 32,0 & 15 & 15,0 & 100 & 100 \\
\hline $\begin{array}{l}\text { 9. Pagamento de contas, } \\
\text { taxas e tributos nos } \\
\text { terminais. }\end{array}$ & 11 & 11,0 & 3 & 3,0 & 8 & 8,0 & 15 & 15,0 & 38 & 38,0 & 25 & 25,0 & 100 & 100 \\
\hline $\begin{array}{l}\text { 10. Forma de operar os } \\
\text { terminais de } \\
\text { autoatendimento }\end{array}$ & 2 & 2,0 & 1 & 1,0 & 5 & 5,0 & 15 & 15,0 & 42 & 42,0 & 35 & 35,0 & 100 & 100 \\
\hline $\begin{array}{l}\text { 11. Empréstimo e } \\
\text { financiamentos através } \\
\text { dos terminais }\end{array}$ & 43 & 43,0 & 1 & 1,0 & 9 & 9,0 & 17 & 17,0 & 17 & 17,0 & 13 & 13,0 & 100 & 100 \\
\hline $\begin{array}{l}\text { 12. Correção dos erros } \\
\text { cometidos nos terminais } \\
\text { de autoatendimento }\end{array}$ & 24 & 24,0 & 8 & 8,0 & 3 & 3,0 & 21 & 21,0 & 31 & 31,0 & 13 & 13,0 & 100 & 100 \\
\hline $\begin{array}{l}\text { 13. Telefone de auxilio } \\
\text { no interior das salas de } \\
\text { autoatendimento }\end{array}$ & 41 & 41,0 & 3 & 3,0 & 11 & 11,0 & 17 & 17,0 & 20 & 20,0 & 8 & 8,0 & 100 & 100 \\
\hline $\begin{array}{l}\text { 14. Sistema de câmera de } \\
\text { video para registro da } \\
\text { movimentaçãopessoas }\end{array}$ & 21 & 21,0 & 1 & 1,0 & 4 & 4,0 & 14 & 14,0 & 36 & 36,0 & 24 & 24,0 & 100 & 100 \\
\hline
\end{tabular}

Na tabela 3, é possível observar que, de modo geral, todos os itens questionados foram bem avaliados, à exceção da operação de empréstimos e financiamentos através do uso de terminais, assim como a existência de telefone de auxílio no interior das salas de autoatendimento, que tiveram elevados índices de não resposta.

O elevado índice de resposta em relação a esse aspecto permite concluir que os entrevistados, prioritariamente, efetuam saques e depósitos de valores, consulta de saldos, extratos e aplicações através de caixas eletrônicos. A preferência por esse serviço parece decorrer da sua existência há mais tempo e, além disso, ao fato de que os clientes encontram, no autoatendimento, a possibilidade de receber auxílio imediato. $O$ caixa eletrônico é o instrumento mais utilizado pelos entrevistados, pois, além de dispor dos mesmos serviços on-line, de forma adicional, ainda é capaz de fornecer valores em dinheiro, talões de cheque e a possibilidade de efetuar depósitos. 
Portanto, o conhecimento acerca desses clientes possibilita ao banco prestar serviços diferenciados, atendendo melhor as expectativas dos clientes que gostam de rapidez, comodidade e atendimento, de forma mais personalizada.

\subsubsection{Satisfação do usuário com o serviço de atendimento telefônico}

Os principais aspectos que influenciam a satisfação com os serviços de atendimento telefônico são apresentados na tabela 4.

Tabela 4 - Satisfação com o serviço de atendimento telefônico

\begin{tabular}{|c|c|c|c|c|c|c|c|c|c|c|c|c|c|c|}
\hline \multirow[t]{2}{*}{-} & \multicolumn{2}{|c|}{$\begin{array}{l}\text { Não } \\
\text { resposta }\end{array}$} & \multicolumn{2}{|c|}{$\begin{array}{l}\text { Muito } \\
\text { Insatisfeito } \\
\text { (1) }\end{array}$} & \multicolumn{2}{|c|}{ (2) } & \multicolumn{2}{|c|}{ (3) } & \multicolumn{2}{|c|}{ (4) } & \multicolumn{2}{|c|}{$\begin{array}{l}\text { Muito } \\
\text { satisfeito } \\
\text { (5) }\end{array}$} & \multicolumn{2}{|c|}{ Total } \\
\hline & $\mathrm{N}$ & $\%$ & $\mathrm{~N}$ & $\%$ & $\mathrm{~N}$ & $\%$ & $\mathrm{~N}$ & $\%$ & $\mathrm{~N}$ & $\%$ & $\mathrm{~N}$ & $\%$ & $\mathrm{~N}$ & $\%$ \\
\hline $\begin{array}{l}\text { 1. Rapidez no } \\
\text { atendimento nas } \\
\text { centrais telefônicas }\end{array}$ & 52 & 52,0 & 4 & 4,0 & 9 & 9,0 & 21 & 21,0 & 10 & 10,0 & 4 & 4,0 & 100 & 100 \\
\hline $\begin{array}{l}\text { 2. Educação e } \\
\text { atenção dos } \\
\text { atendentes das } \\
\text { centrais telefônicas }\end{array}$ & 48 & 48,0 & 3 & 3,0 & 6 & 6,0 & 18 & 18,0 & 16 & 16,0 & 9 & 9,0 & 100 & 100 \\
\hline $\begin{array}{l}\text { 3. Agilidade na } \\
\text { solução de dúvidas e } \\
\text { problemas registrados }\end{array}$ & 49 & 49,0 & 3 & 3,0 & 9 & 9,0 & 19 & 19,0 & 11 & 11,0 & 9 & 9,0 & 100 & 100 \\
\hline $\begin{array}{l}\text { 4. Aplicações e } \\
\text { resgates de } \\
\text { investimentos } \\
\text { através do telefone }\end{array}$ & 60 & 60,0 & 1 & 1,0 & 5 & 5,0 & 13 & 13,0 & 16 & 16,0 & 5 & 5,0 & 100 & 100 \\
\hline $\begin{array}{l}\text { 5. Horário de } \\
\text { Funcionamento das } \\
\text { centrais telefônicas }\end{array}$ & 53 & 53,0 & 2 & 2,0 & 5 & 5,0 & 17 & 17,0 & 14 & 14,0 & 9 & 9,0 & 100 & 100 \\
\hline $\begin{array}{l}\text { 6. Consulta de saldos } \\
\text { ou extratos por } \\
\text { telefone }\end{array}$ & 58 & 58,0 & 3 & 3,0 & 5 & 5,0 & 11 & 11,0 & 11 & 11,0 & 12 & 12,0 & 100 & 100 \\
\hline $\begin{array}{l}\text { 7. Operações no } \\
\text { sistema eletrônico }\end{array}$ & 53 & 53,0 & 2 & 2,0 & 6 & 6,0 & 16 & 16,0 & 15 & 15,0 & 8 & 8,0 & 100 & 100 \\
\hline
\end{tabular}

Conforme se pode observar na tabela 4, o índice de não resposta foi bastante elevado nesse aspecto, demonstrando que os entrevistados desconhecem esse serviço ou, até mesmo, nunca o utilizaram. Os dados evidenciam também que, entre aqueles que responderam, cerca de $20 \%$ deles parecem estar satisfeitos com o serviço, especialmente em relação à educação e à atenção dos atendentes, ao horário de atendimento e às operações realizadas.

\subsubsection{Satisfação dos usuários em relação aos serviços do internet banking}

Os principais aspectos que influenciam a satisfação com os serviços de internet banking em relação às operações e as estruturas disponíveis são apresentados na tabela 5. 
Tabela 5 - Satisfação com os serviços de internet banking

\begin{tabular}{|c|c|c|c|c|c|c|c|c|c|c|c|c|c|c|}
\hline \multirow[t]{2}{*}{$\begin{array}{l}- \\
- \\
-\end{array}$} & \multicolumn{2}{|c|}{$\begin{array}{l}\text { Não } \\
\text { resposta }\end{array}$} & \multicolumn{2}{|c|}{$\begin{array}{c}\text { Muito } \\
\text { Insatisfeito } \\
\text { (1) }\end{array}$} & \multicolumn{2}{|c|}{ (2) } & \multicolumn{2}{|c|}{ (3) } & \multicolumn{2}{|c|}{ (4) } & \multicolumn{2}{|c|}{$\begin{array}{l}\text { Muito } \\
\text { satisfeito } \\
\text { (5) }\end{array}$} & \multicolumn{2}{|c|}{ Total } \\
\hline & $\mathrm{N}$ & $\%$ & $\mathrm{~N}$ & $\%$ & $\mathrm{~N}$ & $\%$ & $\mathrm{~N}$ & $\%$ & $\mathrm{~N}$ & $\%$ & $\mathrm{~N}$ & $\%$ & $\mathrm{~N}$ & $\%$ \\
\hline $\begin{array}{l}\text { 1. Layout da } \\
\text { página }\end{array}$ & 39 & 39,0 & 3 & 3,0 & 1 & 1,0 & 13 & 13,0 & 25 & 25,0 & 19 & 19,0 & 100 & 100 \\
\hline $\begin{array}{l}\text { 2.Navegação } \\
\text { do site }\end{array}$ & 37 & 37,0 & 4 & 4,0 & 2 & 2,0 & 14 & 14,0 & 28 & 28,0 & 15 & 15,0 & 100 & 100 \\
\hline $\begin{array}{l}\text { 3.Agilidade e } \\
\text { rapidez do } \\
\text { cadastro site }\end{array}$ & 38 & 38,0 & 4 & 4,0 & 4 & 4,0 & 17 & 17,0 & 22 & 22,0 & 15 & 15,0 & 100 & 100 \\
\hline $\begin{array}{l}\text { 4.Execução de } \\
\text { tarefas sem } \\
\text { erro }\end{array}$ & 40 & 40,0 & 4 & 4,0 & 1 & 1,0 & 24 & 24,0 & 21 & 21,0 & 10 & 10,0 & 100 & 100 \\
\hline $\begin{array}{l}\text { 5. Solução de } \\
\text { problemas }\end{array}$ & 43 & 43,0 & 3 & 3,0 & 7 & 7,0 & 10 & 10,0 & 29 & 29,0 & 8 & 8,0 & 100 & 100 \\
\hline $\begin{array}{l}\text { 6.Suficiência } \\
\text { das } \\
\text { informações }\end{array}$ & 46 & 46,0 & 3 & 3,0 & 3 & 3,0 & 15 & 15,0 & 21 & 21,0 & 12 & 12,0 & 100 & 100 \\
\hline $\begin{array}{l}\text { 7.Segurança } \\
\text { das } \\
\text { transações }\end{array}$ & 44 & 44,0 & 4 & 4,0 & 5 & 5,0 & 8 & 8,0 & 24 & 24,0 & 15 & 15,0 & 100 & 100 \\
\hline $\begin{array}{l}\text { 8.Identificação } \\
\text { necessidades } \\
\text { específicas } \\
\text { dos clientes. }\end{array}$ & 41 & 41,0 & 6 & 6,0 & 3 & 3,0 & 14 & 14,0 & 23 & 23,0 & 13 & 13,0 & 100 & 100 \\
\hline
\end{tabular}

À exemplo do serviço telefônico, o internet banking também apresentou elevado índice de não resposta. Entretanto, o resultado entre aqueles que responderam o índice de satisfação com o serviço é de cerca de $50 \%$ e, portanto, bastante superior ao apresentado pelo serviço telefônico.

Entre os principais aspectos, destacam-se layout da página do internet banking e navegação do site. Isso se deve, provavelmente, à versatilidade do serviço, permitindo maior gama de operações e maior autonomia ao usuário.

\subsection{Avaliação da satisfação geral dos usuários com os serviços oferecidos}

No gráfico 5, são apresentadas as médias gerais atribuídas pelos clientes aos serviços de forma particularizada e aos serviços de maneira geral. 


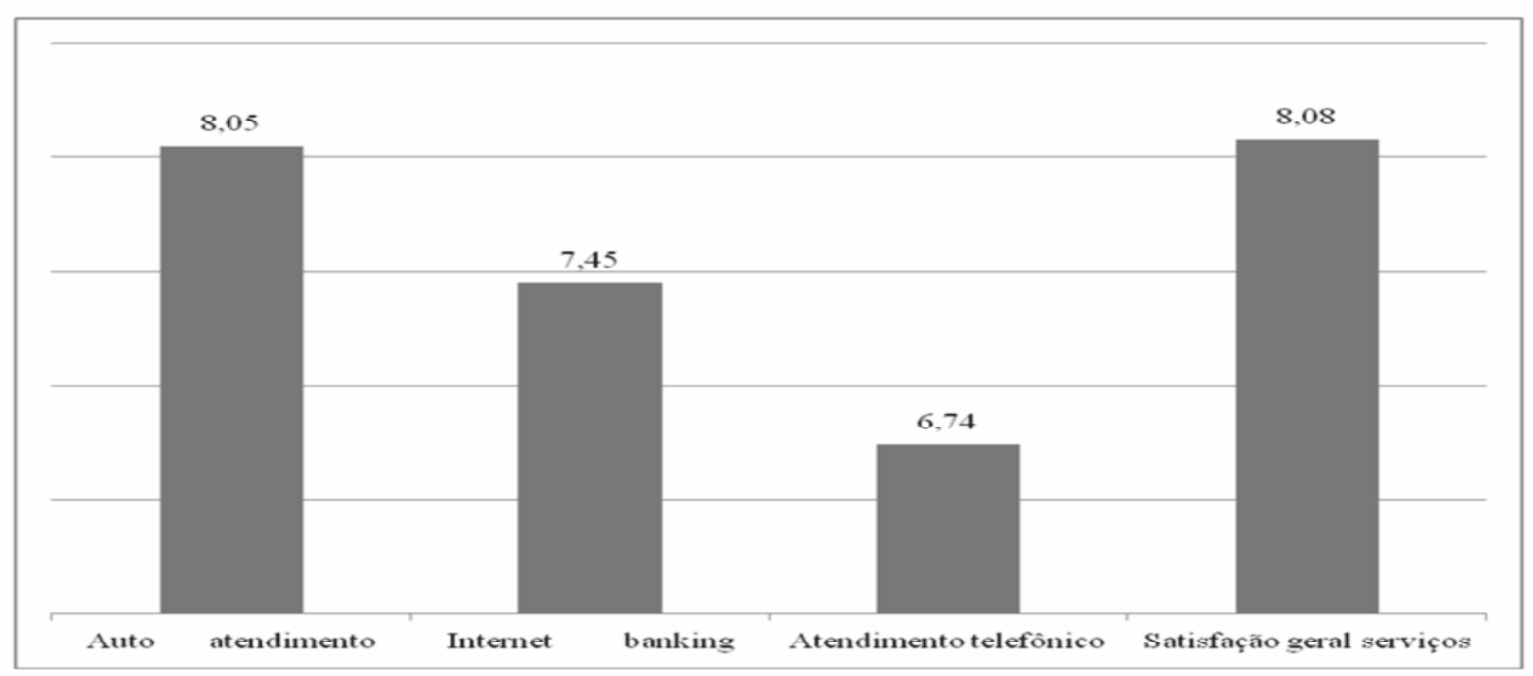

Gráfico 5 - Avaliação da satisfação geral com os serviços oferecidos

Corroborando-se os itens avaliados anteriormente, o serviço melhor avaliado é o de autoatendimento, seguido do internet banking. Apesar de o serviço de atendimento telefônico ser o item com menor nível de aprovação, a média geral de aceitação dos serviços oferecidos pelo Banco do Brasil é bastante elevada (superior a 8,0).

Mais uma vez, os resultados vão ao encontro do constatado por Henrique (2001) ao concluir que a satisfação dos clientes Banco do Brasil está próxima ao nível máximo em praticamente todos os aspectos referentes às centrais telefônicas, ao autoatendimento, ao internet banking e à empresa como um todo.

\section{CONSIDERAÇÕES FINAIS}

Cada vez mais, as instituições financeiras devem visar à conquista de novos clientes e à fidelização dos clientes atuais. O Banco do Brasil, por sua história de vanguarda, em seu segmento de atuação, está inserido nessa ótica e vem buscando, ao longo do tempo, reconhecimento na sua área de atuação. Para tanto, pensar em uma estratégia que priorize a gestão de serviços torna-se fundamental para a concretização dos seus interesses.

O estudo realizado buscou avaliar a percepção dos clientes entrevistados em relação aos serviços de atendimento oferecidos pela instituição. Foram entrevistados clientes do Banco do Brasil na cidade de Santa Maria, RS.

Inicialmente, foi identificado o perfil dos clientes entrevistados, formado por pessoas jovens e economicamente ativas, por estudantes e por pessoas oriundas das agências Niederauer e Avenida Rio Branco, agências centrais da cidade.

A seguir, foi analisado o grau de utilização dos serviços de autoatendimento, telefone e internet banking. Os dados revelaram a preferência dos clientes pela utilização de terminais de autoatendimento, que implicam a frequência às agências ou a terminais 24 horas. 0 serviço telefônico e o de internet apresentam baixa frequência de uso, destacando-se o elevado percentual de clientes que nunca acessaram a estes. .

A satisfação dos usuários em relação aos serviços de autoatendimento, telefone e internet, foi outro aspecto avaliado. O caixa eletrônico é o instrumento mais utilizado pelos entrevistados, pois, além de dispor dos mesmos serviços on-line, de forma adicional, ainda é capaz de fornecer valores em dinheiro, talões de cheque e possibilidade de efetuar depósitos. Chama atenção, em 
relação ao serviço telefônico e ao internet banking, o elevado índice de não resposta, revelando a pouca utilização desses serviços.

A avaliação da satisfação geral dos usuários com os serviços oferecidos foi também verificada. Corroborando os itens avaliados anteriormente, o serviço melhor avaliado é o de autoatendimento, seguido do internet banking. Apesar de o serviço de atendimento telefônico ser o item com menor nível de aprovação, a média geral de aceitação dos serviços oferecidos pelo Banco do Brasil é bastante elevada.

De modo geral, os resultados confirmam o perfil dos clientes participantes da pesquisa como um perfil social e cultural mais elevado, de quem valoriza, em maior profundidade, os aspectos que estabelecem relacionamento de longo prazo com o banco. Os clientes estão satisfeitos com os serviços oferecidos pelo banco. Observa-se, apenas, que os serviços de atendimento externos à agência, como o telefone e o internet banking, devem ser desenvolvidos em razão de hábitos e posturas culturais.

A análise de resultados evidenciou a falta de questionamentos em relação às tecnologias móveis, uma tendência no serviço de atendimento bancário. Também foi identificada a falta de questionamentos em relação às principais categorias de aplicativos, em cada serviço avaliado. Como proposta para novas pesquisas nessa área, sugere-se o estudo comparativo com as agências da cidade de Santa Maria, para que se possam discutir e avaliar as diferenças de comportamentos e práticas gerenciais envolvidas. $O$ estudo não se conclui aqui, pois apresenta uma série de possibilidades que podem ser estudadas para que essa temática seja enriquecida ainda mais. 


\section{REFERÊNCIAS BIBLIOGRÁFICAS}

ARAÚJO, L. C. G. de. Organização, sistemas e métodos. São Paulo: Atlas, 2001.

ANDREZO, A. F.; LIMA, I. S. Mercado Financeiro, Aspectos Históricos e Conceituais. Disponível em: $\quad$ http://resumos.netsaber.com.br/ver_ resumo_c_2995.html. Acesso em junho de $201 \overline{1}$.

BANCO DO BRASIL. Disponível em: http://www. bb.com.br/portalbb. Acesso em 30 julho 2011.

CASTRO, L. A. M. H. de M. E.; GOUVÊA, M. A. Os fatores de alavancagem da qualidade dos internetbankings. Revista de Administração da UFSM, Santa Maria, v. 4, n.1, p. 125-143, jan./abr. 2011.

CAVALCANTE, L. R. Sistema financeiro no Brasil: uma breve análise de sua evolução. Bahia Análise \& Dados, v.12, n.3, p.199-210, 2002.

COSTA FILHO, B. A. Automação Bancária: uma análise sob a ótica do cliente. 1996. Dissertação (Mestrado em Administração) - Faculdade de Economia, Administração e Contabilidade, Universidade de São Paulo, São Paulo, 1996.

CURRAN, J. M., MEUTER, M. L. Self service technology adoption: Comparing three technologies. Journal of Services Marketing, $v$. 19, n.2, p. 103-114, 2005.

DAVIS, F. D. A Technology Acceptance Model for empirically testing new end-user information systems: theory and results. 1986. Tese (Doutorado em Administração) -Sloan School of Management Science, Massachusetts Institute of Technology, Cambridge, 1986.

DIAS, M. C.; ZWICKER, R.; VICENTIN, I. C. Análise do modelo de aceitação de tecnologia de Davis. Revista SPEI, Curitiba, v. 4, n. 2, p. 1523, jul./dez. 2003. Disponível em: http://Web. spei.br:8081/f a culd a d e s/revis ta / re vis ta_V 4 _n 2 /analise_modelo.pdf. Acesso em: 28 fev. 2011.

DINIZ, E. H. Uso da Web nos serviços financeiros. São Paulo: Núcleo de pesquisas e publicações - Fundação Getúlio Vargas (EASP/ FGV/NPP), 2001. 198 p.
FABENY, G. Fatores geradores de resistência ao uso do internet banking no Banco do Brasil S.A.: um estudo de caso na agência de Itapema SC. 2007. Trabalho de conclusão (Especialização em Administração) - Universidade Federal do Rio Grande do Sul, Porto Alegre, 2007.

FEBRABAN. CIAB FEBRABAN 2011. A Tecnologia além da Web. Disponível em: <http://www. febraban.org.br>. Acesso em 03 junho de 2011.

GOUVEIA, F. Inovações tecnológicas priorizam mobilidade e segurança ao cliente. Inovação Uniemp, v.3, n. 6, 2007.

HAYTKO, D. L., SIMMERS, C. S. What's your preference? An exploratory examination of the effect of human vs ATMS online interactions on overall satisfaction with banking services. Management Research News, v. 32, n. 4, 2009.

HENRIQUE, J. L. Satisfação do usuário com as tecnologias da informação nos serviços bancários. 2001. Dissertação (Mestrado em Administração) - Universidade Federal do Rio Grande do Sul, Porto Alegre, 2001.

KOTLER, P. Administração de marketing: análise, planejamento, implementação e controle. 5 ed. São Paulo: Atlas, 1998.

LAS CASAS, A. L. Marketing conceitos, exercícios, casos. 4 ed. São Paulo: Atlas, 1997.

LAUDON, K. C.; LAUDON, J. P. Sistemas de Informação com Internet. 4 ed. São Paulo: Editora JC, 2004.

MATTAR NETO, J. A. Metodologia científica na era da informática. São Paulo: Saraiva. 2002.

PEREIRA, V. A. Práticas de Comunicação e Linguagens Publicitárias nos Meios Digitais: Explorando o Projeto Transficção. In: XXIX Congresso Brasileiro de Ciências da Comunicação, Brasília, 2006.

PIKKARAINEN, K. et al. The measurement of end-user computing satisfaction of online banking services: empirical evidence from Finland. International Journal of Bank Marketing, v. 24, n.3, p. 158-172, 2006.

PINSONNEAULT, A.; KRAEMER, K. L. Survey research in management informations systems: 
an assessement. Journal of Management Information Systems, v.10, n. 2, p. 75-106, 1993.

RICHARDSON, R. J. Pesquisa Social: métodos e técnicas. São Paulo: Atlas, 1999.

SEGNINI, L. R. P. Reestruturação nos Bancos no Brasil: Desemprego, subcontratação e intensificação do trabalho. Educação \& Sociedade, ano XX, n. 67, Agosto, 1999.

TEIXEIRA, F. L. C.; CAVALCANTE, L. R. M. T. Relações entre tecnologia, padrões organizacionais e produtividade no setor bancário no Brasil. Revista de Administração, São Paulo, v.40, n.3, jul./ago./set., p.213-224, 2005.

TRIVINOS, A. N. S. Introdução a pesquisa em ciências sociais: a pesquisa qualitativa em educação. São Paulo: Atlas, 1987.

TURBAN, E., LEE, J., KING, D., CHUNG, H. $M$. Electronic commerce: a managerial perspective. New Jersey: Prentice-Hall, 1999.

ZEITHAML, V.; BITNER, M. J. Marketing de serviços: a empresa com foco no cliente. Porto Alegre: Bookman, 2003. 